\title{
Application of knowledge management as a Human Resource (HR) strategy tool in Zimbabwean Universities.
}

\author{
Nyamubarwa, Willard \\ Department of Psychology \& Human Resource Management/ Great Zimbabwe University, Zimbabwe
}

\begin{abstract}
The study aimed to explore the extent to which knowledge management activities are being applied in Human Resource (HR) functions and practices in Zimbabwean Universities. The research was premised on the Nonaka's Knowledge Creation Process Model. The study employed a descriptive survey design within the qualitative research paradigm to solicit for the research data. Purposive sampling was used to select the study respondents from 6 of the 10 universities in Zimbabwe. The study revealed that HR departments in Zimbabwean universities are using knowledge management as a strategy albeit to a limited extent in the areas of recruitment and selection, training, and to a certain extent in rewards management. HR departments are also facilitating the creation of "communities of practice" which are considered important in knowledge management activities. The HR departments were however found wanting in the promotion of externalisation, combination and internalisation as well as the creation of an appropriate communication, structural and cultural environment (Ba). It was recommended that the HR departments should introduce knowledge sharing as an attribute in their recruitment and selection policies, promote the establishment of a knowledge sharing culture, incorporate knowledge management practices in their training policies as well as use knowledge management as a metric in performance evaluation.
\end{abstract}

Keywords: academia, human resource, knowledge, strategy, Zimbabwe

\section{Introduction}

Knowledge management has been hyped as the latest fad to occupy management discourse today (Millmore et al 2007, p.377). This shift to knowledge management has been necessitated by a shift away from the traditional labour intensive organisations to the modern day high-tech industries which rely on knowledge workers (ibid). In the new knowledge economy, value addition is achieved by the development and utilisation of existing and new knowledge to enhance organisation efficiency, effectiveness and innovation. This is in contrast to the use of traditional factors of production, land, labour and enterprise (ibid). Managers today are continually strategising on how to effectively direct their employee knowledge assets to strengthen the strategic performance of their organisations (Carter \& Scarborough 2001). Therefore to construct an organisation that is able to deliver on its strategic plans, Human Resource (HR) managers and other line managers need to properly staff their organisations, build fundamental abilities, and arrange the organisational processes to leverage the knowledge held by the employees (Davenport and Prusak 1998).

Prusak (1999, p.6) defines knowledge as "what an organisation knows, how it uses it and how fast it can know something new" The minds of employees employed in organisations are embedded with knowledge about organisational routines, processes, practices, systems, software and norms that they use in their daily working experiences (Hislop 2003). The information is also embedded in official documents and information repositories (Leopold, et. al; 2005).

Zimbabwe currently boasts of 8 state-owned and 3 private universities. All these universities are multidisciplinary offering a number of degrees in a number of disciplines. The most important goal of any university in Zimbabwe and beyond is to generate, disseminate and foster the application of new knowledge in nation building. This places the university's HR departments in a position to use different knowledge management strategies as tools to drive the overall university's HR strategy. The field of knowledge management and its applicability in HR systems in Zimbabwe has not been researched adequately and there is little knowledge on the ground.

\section{Statement of the Problem}

Knowledge is today viewed as a critical organisational resource which is a critical source of competitive advantage (Torrington, Hall \& Taylor 2005 p.248). Universities generate a lot of information and knowledge during the teaching and research processes. Likewise universities employ knowledge workers who produce and acquire knowledge in their day-to-day work activities. University HR departments can take advantage of this state of affairs to craft appropriate knowledge based HR strategies. This research intends to find out how HR departments in Zimbabwean universities are using the knowledge environment they are 
operating from and the knowledge at their disposal to craft appropriate strategies that supports the university's overall strategic goals. The findings will be used to build on the existing information base and to make recommendations for adoption by other university HR departments in Zimbabwe, regionally and abroad. In addition scant research has been conducted in the application of knowledge management in Zimbabwean university HR departments and it is envisaged that this study will fill that knowledge gap.

\section{Research objectives}

This study is guided by the following objectives

1. To identify trends in knowledge management in Zimbabwean universities.

2. Identify the extent to which knowledge management is practiced in university HR departments.

3. To identify factors that hinder knowledge generation and sharing in the university sector.

\section{Theoretical Framework}

Nonaka, Toyama and Konno's (2000) Knowledge Creation Process Model was taken as a theoretical guide to this research.

\subsection{Assumptions of the model}

- The raison d'être of any organisation is to continuously create knowledge.

- Organisations create and develop knowledge to solve organisational problems.

- Knowledge workers are motivated by the need for personal growth, occupational autonomy, task achievement and by monetary rewards.

According to the model any organisation operating in the contemporary knowledge economy should be able to use the 4 levers of knowledge management to support organisational objectives. The elements are:

1) SECI - Socialisation, Externalisation, Combination and Internalisation process. This is the process of knowledge creation through the inter-conversion between tacit and explicit knowledge.

2) $\mathbf{B a}$ - This term derived from the Japanese word meaning "place" refers to the shared context for knowledge creation. In other words this refers to the organisational climate or culture where information is interpreted to become knowledge. Ba is not merely a physical place but rather unifies the physical space such as office space, virtual space such as email and mental space such as shared ideals (Little 2006, p.30)..

3) Knowledge Assets - this refers to the inputs, outputs and moderators of the knowledge creation process. In other words these are the employees in the organisation who drive and utilise knowledge in their day-to-day work activities.

4) The SECI Process - An organisation creates knowledge through the interaction between tacit and explicit knowledge. This interaction is called knowledge conversion. Through this conversion process, tacit and explicit knowledge expand both in quality and quantity. There are four modes of knowledge conversion under the SECI process; socialisation, externalisation, combination and internalisation.

Socialisation is the process of sharing new tacit knowledge through the process of socialisation and sharing experiences (Shukla \& Srinivasan 2000). Since tacit knowledge is difficult to formalise and articulate and is sometimes context specific, (Millmore et al 2007, p.381) it can only be acquired through shared experience such as spending time together or sharing the same environment.

On the other hand, externalisation refers to the process of articulating tacit knowledge into explicit forms or concepts. When tacit knowledge is made explicit, knowledge is crystallised thus allowing it to be shared by others and in the process become a basis for new knowledge. The publication of research findings into books, papers or manuals is an example of knowledge externalisation.

The third aspect is Combination which is the process of sharing explicit knowledge within organisations. Explicit knowledge is collected from inside and outside the organisation and then combined, edited or processed to form new explicit knowledge. The new explicit knowledge can be shared or disseminated to the rest of the organisation through meetings, documents, telephonic conversations or through computer networks. The organisation may also use computerised communication networks and databases to facilitate this model of knowledge conversion. Finally, internalization involves embodying explicit knowledge into tacit knowledge. Explicit knowledge created in an organisation is shared throughout the organisation and converted into tacit knowledge by individuals.

\section{Conceptual Framework}

Managers and academics have recognized knowledge as a key source of competitive advantage (Grant, 1997). Knowledge is a potentially significant resource to the firm as it may possess valuable, rare, inimitable and non-substitutable characteristics particularly if it has a tacit dimension (Polanyi, 1966; Hall and Sapsed, 2005). The ever increasing importance of knowledge in contemporary society calls for a shift in our thinking concerning innovation in business organizations - be it technical innovation, product or process innovation, 
strategic or organizational innovation. It raises questions about how organizations create new knowledge and, more importantly, how they transfer new knowledge. Innovation, which is a key form of organizational knowledge creation, cannot be explained sufficiently in terms of information processing or problem solving (Alwis and Hartmann;2008). Innovation can be better understood as a process in which the organization creates and defines problems and then actively develops new knowledge to solve them (Nonaka, 1994, p. 14). Davenport and Marchand suggest that: "whilst knowledge management does involve information management, beyond that it has two distinctive tasks: to facilitate the creation of new knowledge and to manage the way people share and apply it'' (Davenport and Marchand, 1992).

Torrington, et al (2005) recommend that HR managers need to craft organisational structures and systems that promote knowledge dissemination as well as train people to gain knowledge accessing skills". Armstrong (2003, p.159) concurs and says knowledge management is concerned with people in organisations and how these people acquire, share and disseminate knowledge in their daily work activities. This knowledge flows throughout the organisation through management information systems and through "traditional" methods like meetings, workshops, courses, the intranet and written correspondence. Blake (1998) views the purpose of knowledge management as "to capture an organisation's collective expertise and distribute it to whenever it can achieve the biggest payoff'. This according to Armstrong (2003, p.160) suggests that the source of competitive advantage in many organisations lies in its human capital, not in how the organisation positions' itself in the market.

In terms of the Human Resource Management (HRM) function, the rise of the knowledge economy has had a big impact with a shift away from HRM as a bureaucratic "personnel management" function to the development of modern day HRM (Gloet, 2006). Indeed a number of researchers warn that HRM faces extinction if it does not respond to changes brought about by the shift from a traditional to a knowledge based economy. (Lengnick-Hall, 2003; Saint-Onge, 2001; Stewart, 1997). Under the knowledge economy HRM's traditional role of managing people has been broadened to include managing organisational capabilities, relationships as well as learning and knowledge (Lengnick-Hall 2003). This involves developing themes and creating environments conducive to learning as well as to the acquisition, sharing and dissemination of knowledge within organisations. Lengnick-Hall \& Lengnick-Hall (2003) suggest a "revitalisation" of the HR function to respond to the demands of the new knowledge economy. Such revitalisation entails the assumption of new roles, responsibilities and strategic focus (Gloet 2003). New HR roles include those of the human capital steward, knowledge facilitator, relationship builder and a rapid deployment specialist (Gloet 2003). Consequently, it was argued by Carter and Scarborough (2001) that HRM strategies should focus on creating the conditions for knowledge sharing through recruitment policies and rewarding such behaviour. HR may lobby the strategic planning processes to develop vision statements which spell out the organisation's aims to achieve competitive advantage by developing and effectively using knowledge and that to achieve that aim, sharing knowledge is seen as a core value (Armstrong 2003). This incorporation of knowledge management in the strategic management planning of the organisation lays the groundwork for the effective implementation of knowledge management activities in the organisation (ibid). Torrington, Hall and Taylor (2005, p.254) suggest that HR managers need to formulate organisational structures and processes that promote knowledge diffusion and in the creation of systems that support knowledge access, training employees in their use, provide mechanisms for sharing knowledge as well as foster a "knowledge-centric culture" in the workplace.

Knowledge in organizations need to be secured if it is to make any meaningful contributions to organizational success. As Randeree (2006) notes, if knowledge is determined to be the most important resource of the firm, then clearly the need to secure that resource must be a primary responsibility. If knowledge is power and a source of competitive advantage (Salisbury, 2003), then there needs to be special attention given to securing knowledge and knowledge repositories within the firm to protect the core assets of the organization.

Secure knowledge management activities include: limiting the number of employees who have access to certain information, making sure no single employee has access to the majority of information surrounding a new product, and maintaining a causal ambiguity around a firm's ability to successfully compete (Bloodgood and Salisbury, 2001). Limiting employees with access provides a mechanism for firms to only give key personnel access to critical knowledge. A second security activity involves keeping all the information out of the hands of one employee. This is done for competitive reasons. With increased mobility of employees between firms, knowledge concentrated in one or a small group of individuals can be a threat to the competitiveness of the firm. Employees can leave the firm taking the knowledge with them - especially the tacit knowledge captured in the organization. Another concern with concentrating knowledge in one individual occurs if that individual retires or is ill (Randeree;2006).

Nowadays in our fast-changing environment innovations are key for business survival (Alwis and Hartman; 2006). It is imperative for management to be aware of factors contributing to the development of new strategies, new products and new ways of manufacturing, distributing and selling. In such organizations the HR department can take advantage of the various opportunities availed by knowledge management to help their 
organizations achieve sustainable competitive advantage. In a recent empirical study Länsisalmi et al. (2004) focused on six types of barriers of innovation: underutilization of knowledge, skills and abilities, lack of resources, lack of communication and cooperation, non-supportive managerial behavior, non-supportive reward systems and innovative activities considered as unimportant. However, innovative HR departments are always best placed to surmount these challenges.

\section{Research Methodology}

The study employed a descriptive survey design within the qualitative research paradigm. The design was employed to gather the opinions and perceptions of HR managers on the knowledge management practices in use in the Zimbabwean academic sector. A non-random, convenient sample from the 5 universities HR departments and other HR supporting structures such as the Information Technology (IT), The Research Board and the Library were selected for the research. Convenience sampling was necessitated by the limited finance and time at the disposal of the researcher. Stratified random sampling was used to select 30 members of Teaching Staff and 20 members of Support Staff for inclusion in the research sample. The relatively large size of the sample would ensure a high degree of generalisability of findings for all the universities in Zimbabwe. Using an interview guide to ensure consistency in the interview content, the researcher questioned key university managers in the identified departments. All interviews were audio-taped and transcribed verbatim. Given the nature of the topic, which entailed soliciting attitudes and opinions on a social phenomenon, a qualitative, interpretivist approach was most appropriate. Data were coded and categorised using the Miles and Huberman (1994) method of data analysis. Major themes identified in the data revolved around the five set objectives.

\section{Findings \& Discussion}

All respondents agreed that they belonged to some formal socialisation structure at their respective universities. These included the local Worker's Committees and other many other various associations. In addition all respondents indicated that they belonged to other informal out of work socialisation clubs. No respondent cited any financial aid as coming from HR to support their clubs/associations.

The professional associations cited by the respondents included 10 local ones which included, the Law Society of Zimbabwe, the Economics Society of Zimbabwe, Biotechnology Association of Zimbabwe, IPMZ and MISA among others. Some respondents revealed that they are members of regional and international associations and 12 associations were mentioned. The following associations intrigued the researcher

- Social Science Research in Eastern and Southern Africa

- World Association of Radio Broadcasters

- Commonwealth Association of Museums

- African Languages Association for Lexicography

The interview carried out on the HR Department's staff revealed that the department support the existence and formation of various clubs and association where employees might socialise.

\subsection{ICT and Knowledge SECI}

The IT system provided another forum for socialisation. However, the ICT department as a strategic arm of the university's information delivery and knowledge sharing does not seem to have any working relationship with the HR department. This state of affairs was identified across all universities under study. The interviews revealed that the two departments act as autonomous entities with each department not aware of what the other department is doing. The same state of affairs was also identified in the relationship between the HR department and the Research Board and the Library in supporting knowledge externalisation activities. According to Borghoff (2008) ICT systems in an organisation provides a forum for employee socialisation and the proper transfer of knowledge across the whole organisation. The University's various computer labs were identified as an important forum for employee socialisation and sharing of tacit knowledge. This proves the fact that the University's ICT systems are contributing to the sharing of tacit knowledge as well as the internalisation of knowledge by university employees. However, the fact that the HR departments do not make use of the ICT department to promote this socialisation, combination or internalisation of knowledge reveals the limitation to the knowledge management trends at in all universities in Zimbabwe.

Communities of practice are an essential element in all knowledge management activities (LengnickHall \& Lengnick-Hall 2005). It is HR's role to invest in the building of communities of practice in the organisation since this directly contributes to the creation of a competitive advantage through employee socialiosation (ibid). The membership of a number of university employees to a variety of professional organisations indicates that University employees are members of communities of practice. This reflects the fact that University employees are engaged in socialisation activities that help in the generation and passing on of 
tacit knowledge on a local scale, in Zimbabwe as in the case of "Law Society of Zimbabwe", regionally as exemplified by "African Languages Association of Lexicography" and internationally as in "Commonwealth Association of Museums". This wide reach of the communities of practice in which Zimbabwean university employees are members and their variety shows to a large degree the high levels of tacit knowledge sharing on the ground.

However, the fact that the HR departments do not support the creation of communities of practice" as revealed by the absence of a register for such communities in 3 of the universities surveyed and the fact that respondents from the HR department did not know what "Communities of Practice" are leaves a yawning gap in the HR activities that need to be carried out to by the HR Department to sensitise their staff and departments and then support the creation of such socialisation fora. In addition, the absence of team working initiatives as an HR strategy in support of knowledge sharing also showed the limitations of the current knowledge management trends applied by the HR departments in Zimbabwe.

\subsection{Library systems and SECI}

The library in a university setting becomes the focal point for knowledge socialisation, externalisation, combination and internalisation (Franklin \& Hodgkinson;2007). However, the interview with the key library staff members revealed that almost all libraries surveyed were facing a number of challenges in service delivery. The fact that the library is said to be failing to secure enough material makes knowledge combination and internalisation difficult in Zimbabwean university libraries. This failure by the library department to deliver in terms of knowledge combination and internalisation as validated by the responses of the university employees who are the potential users of the library services. A cumulative $83 \%$ of these respondents felt that the library was failing to deliver and in this shows that though knowledge management may be in operation at in their libraries, it is still wanting in terms of effective in terms of Combination and Internalisation of knowledge.

Most respondents cited the cost of acquiring material in the face of dwindling budgetary allocations as the biggest challenge. When asked what cost was involved in acquiring local research publications, the respondents highlighted that the acquisition of locally published material was being hindered by bureaucratic red tape. The creation of the "Institutional Repositories "by the respective universities library departments also shows efforts been made to externalise knowledge by the universities. The "Institutional Repository" will provide a database of information that can be accessed by a wide user community therefore promote knowledge externalisation.

The findings also revealed that there are no synergetic relationships between the three crucial arms of knowledge management. This was again confirmed by the questionnaire responses with all respondents citing lack of support from the HR as the major impediment for the establishment of an environment conducive for research and publishing. For example, $88 \%$ of the respondents revealed that they were never asked to reveal any knowledge sharing attributes they have either as part of the recruitment process or at the selection stage. The remaining $12 \%$ said they had been asked for the aptitude to knowledge generation and sharing. This state of affairs was validated by an analysis of the "Recruitment And Selection Policy And Procedure" manuals which revealed that the selection strategy for employees in Zimbabwean universities do not have any requirement for knowledge related attributes. The interview with the senior HR staff respondents revealed that out of the job or person related attributes used in employee selection, "an affinity to acquire, disseminate or share knowledge" is not considered. Furthermore, neither is knowledge aptitude considered in grading employees on initial appointment, instead issues like "experience" are given due consideration. However, the grading procedure takes cognisance of the research history of the candidates. This reveals the knowledge generation ability in all potential employees. The fact that the universities do not consider knowledge acquisition, dissemination and sharing as important job related and employee related attributes in their recruitment and selection procedures shows that the HR department is failing to implement knowledge management in recruiting staff. This means that the selection process does not weed out employees who cannot engage in knowledge generation or sharing activities.

\subsection{Training strategy and SECI}

The concept of training is a core facet of knowledge management (Nonaka, Toyama and Konno;2000). It encompasses all the four knowledge management activities of socialisation, externalisation, combination and internalisation. The training strategy in the various universities surveyed is guided by each institution's respective policy. An analysis of the policies revealed that none of the universities not take cognisance of locally-based training experts (knowledge workers) as resource persons in in-house training sessions. Instead, the training policies puts emphasis in the use of external resource persons. The fact that $68 \%$ of the respondents across all universities have not taken part in any training program paints a picture of a failure to implement knowledge management as an HR strategy by the HR departments in Zimbabwean universities. It means all the knowledge management activities under SECI are not been fully practised. However by placing emphasis on the use of external sources, the university's training policy's are also promoting the transfer of tacit knowledge 
from outside the organisation to members of the organisation. This is important in the support of all knowledge management activities: socialisation, externalisation, combination and internalisation.

\subsection{Performance Management and SECI}

As in the case of training, performance evaluation in Zimbabwean universities is guided by each institution's policy. An analysis of these policies revealed that knowledge generation is used in performance evaluation. This is revealed in the criteria for granting tenure for teaching staff which specifies the need for "satisfactory research". However this metric is applied to Teaching Staff only as Support Staff are appraised using other metrics which are clouded in the term used: "Satisfactory performance of duties as assigned by the respective Head of Department". All Teaching Staff respondents concurred that knowledge generation and externalisation was considered in their Tenure and promotion evaluations. The researcher concluded that, as in in training, knowledge management is applied partially in performance management. However the fact that the knowledge metric is only applied in Tenure applications which is a one off event in the life on employee at the university and not in promotions or annual performance reviews weakens its full applicability. To make matters worse, the same metric is not used in assessing Support Staff who are assessed d on any other variable that the HR department could not put in writing.

\subsection{Rewards Management and SECI}

All universities surveyed did not have a rewards management policy. The researcher had to rely on the interviews in which it was disclosed that there is a clear link between rewards and knowledge generation, dissemination and sharing. Teaching Staff are therefore rewarded according to their teaching hours (knowledge externalisation). There are however no reward incentives for knowledge acquisition (internalisation, combination and socialisation). The interview also revealed that the university maintained a different rewards package for the two categories of staff, Teaching and Support staff. Teaching Staff are rewarded relatively higher than Support Staff even holders of equivalent qualifications. The fact that Teaching Staff are paid disproportionately higher than Support Staff indicate that they are being rewarded as the knowledge generators of the organisation. In addition, since Teaching Staff as knowledge workers are given job autonomy, monetary rewards and an opportunity to achieve their set tasks as proposed by Nonaka and Takeuchi (2000) is further evidence of Zimbabwean universities applying knowledge management in rewards management strategy.

\subsection{Strategic integration and SECI}

The concept of "fit" or strategic integration is considered as a benchmark of human resource management (Beardwell 2004, p.20; Armstrong 2004, p.109). It is defined as the ability of organisations to integrate HRM programs into their strategic plans to ensure that line management functions cohere in the pursuit of organisational objectives. Employees in organisations are seen as key in the implementation of the organisational strategy and therefore the HR strategy should be designed to fit and dovetail with other line functions (ibid). The interviews with the HR, ICT and Library staff in the universities revealed that there are no synergetic relationships between the three line management functions which form the crucial arms of knowledge management. This affects the creation of an enabling environment $(\mathrm{Ba})$ for knowledge management activities. This in other word means that the HR is failing to create an enabling environment (Ba) for knowledge management.

The prevailing organisational culture also acts as an important factor in shaping the attitudes of employees towards knowledge sharing (Carter and Scarborough; 2001). Culture acts to sustain notions of "what counts as knowledge" and "what knowledge is important" (ibid). Bock and Kim (2000) have argued that HRM managers have a pivotal role to play in the shaping and reshaping of an organisation's culture. Therefore, HRM practices can be significant in terms of building and developing the knowledge sharing spirit or culture in an organisation. This knowledge sharing culture does not exist as evidenced by the $80 \%$ respondents who felt they are not willing to share their knowledge with colleagues. The HR department is not doing enough is shaping the organisational culture to be amenable to knowledge sharing.

\section{Conclusion}

This study examined the extent to which the HR departments in Zimbabwean universities are using various knowledge management practices in its day-to-day strategies and operations. The study discovered that the HR departments are applying knowledge management though to limited extent in areas like training, recruitment and section and performance evaluation. However, their efforts are being limited by the lack of strategic integration between the HR department and other line management function and between the HR department and the university's top management, funding limitations for knowledge activities, lack of policy directions amongst other reasons.

The researcher wishes to recommend the following strategies that HR departments can adopt in using 
knowledge management as an HR strategy.

1. Lack of information on the concept of knowledge management- The researcher recommends that HR staff be trained on the concept of knowledge management and its uses in HR functions.

2. Strategic integration. There should be a "fit" between HR functions and activities and other line management functions which have an impact on knowledge generation and dissemination in universities like the Research Board, the Library and ICT department.

3. Lack of support by top university management. There should be vertical integration between the HR department and the university management in pursuing knowledge management as a university wide strategy.

\section{References}

[1]. Armstrong, M., 2003. A handbook of human resource management practice $9^{\text {th }}$ ed. London: Kogan Page

[2]. Beardwell, I. \& Holden, L. 2001 Human Resource Management. Prentice Hall: London

[3]. Bock, G. \& Kim, Y. 2000 Breaking the myths of rewards: An exploratory study of attitudes about knowledge sharing, Information Resources Management Journal, Vol. 15, no.2, pp.14-21. Available http://www.emeraldinsight.com [Accessed 23 August2009]

[4]. Boghoff, U.M. 2008 Information technology for knowledge management. Meylan: Rank Xerox Research Centre. Available from http://www.jucs.org/jucs 3 8/information technology for knowledge/Borghoff U M.pdf [Accessed 23 August2009]

[5]. Carter, Chris \& Scarborough, Harry, 2001 Towards a second generation of KM? The people management challenge. Education \& Training. 43 (4/5), Available from: http://www.emeraldinsight.com [Accessed 20 August 2009]

[6]. Gloet, M. 2003. Knowledge management and the links to HRM. Management Research News, 29 (7), Available from http://www.emeraldinsight.com [Accessed 2 September 2009]

[7]. Hislop, D. 2003 Linking human resource management \& knowledge management via commitment: A review \& research agenda. Employee relations, 25 (2), Available from http://wwwemeraldinsight.com [Accessed 4 September 2009]

[8]. Leopold, M Harrison, P. and Watson, L. 2005 Strategic Human resource management. New Jersey: Prentice-Hall

[9]. Lengnick-Hall, M.L. \& Lengnick-Hall, C.A. 2003 Human resource management in the knowledge economy. San Francisco: BerretKoehler

[10]. Lengnick-Hall, M.L. \& Lengnick-Hall, C.A. 2005 HR's role in building relationship networks. In Little, S. \& Ray, T. eds Managing knowledge: An essential reader $2^{\text {nd }}$ ed. London: Sage

[11]. Little, S. and Ray, T. 2005 Managing knowledge: An essential reader $2^{\text {nd }}$ ed. London: Sage Publications

[12]. Millmore, M. et al 2007. Strategic human resource management: Contemporary issues. Prentice-Hall: Harlow, England

[13]. Nonaka, I, Toyama, R and Konno, N. 2000 SECI, Ba and leadership: A unified model of dynamic knowledge creation In Little, S. \& Ray, T. eds Managing knowledge: An essential reader $2^{\text {nd }}$ ed.. London: Sage

[14]. Prusak, L (ed) 1999. Knowledge in Organisations, Boston: Butterworths Heinemann

[15]. Sax, B. 2005. All that knowledge, so what? Scholarship in the digital university. On the Horizon 13 (4). Avaliable from www.emeraldinsight.com [Accessed 28 October, 2009]

[16]. Shukla, A. \& Srinivasan, R 2000 Knowledge management architecture In: Reddy, Y.K.R. ed. Going global: Leveraging the human potential. New Delhi; Tata McGraw-Hill Publishing, 130-143

[17]. Torrington, D., Hall, H. and Taylor, S. 2005. Human resource management. $6^{\text {th }}$ ed. Harlow, England: Prentice Hall.

[18]. Wenger, E, McDermott, RA \& Snyder, W. 2002 Cultivating Communities of Practice: A guide to Managing Knowledge, Harvard Business School Press: Boston, MA

[19]. Williams, L,Turner, N.and Jones, A. 2008 Embedding universities in knowledge cities. Available from http://www.theworkfoundation.com/assets/docs/publications/208 ideopolis education061208.pdf [Accessed 30 October 2009] 